\title{
Temporal analysis of appetitive behavior following VMH lesions in conscious rats
}

\author{
RONALD H. PETERS and LARRY D. SENSENIG \\ Iowa State University, Ames, Iowa 50010
}

\begin{abstract}
The ventromedial hypothalamus was electrolytically destroyed in 18 conscious, sated rats. Operant responding for food reward on an FR-5 reinforcement schedule increased $2 \mathrm{~h}$ after the lesions were produced. Performance during the hour immediately following the lesions was not affected.
\end{abstract}

An extensive literature has accumulated pertaining to the behavioral consequences produced by bilateral destruction of the ventromedial hypothalamus (VMH) of the rat. Such destruction is typically accomplished by passing either electrolytic or radio-frequency current between various electrode configurations in the anesthetized animal. Lesions are commonly produced by passing anodal current (1-2 mA for 10-20 sec) between the exposed tip of an insulated monopolar stainless steel electrode and a rectal cathode. Rats sustaining VMH lesions are typically permitted several days to recover from surgery prior to behavioral testing. When the time course of the behavioral changes that occur following VMH destruction are of interest, alternatives to this procedure must be used. This report describes a technique that can be used to produce VMH lesions in conscious rats, and shows that these rats increase operant responding for food reward $2 \mathrm{~h}$ after the lesions have been produced.

One of the very obvious behavioral changes in the VMH-lesioned rat is the very large increase in food intake and the subsequent development of obesity (Brobeck, Tepperman, \& Long, 1943; Hetherington \& Ranson, 1940). Hyperphagia often occurs immediately following recovery from surgical anesthesia (Balagura \& Devenport, 1970). Hoebel (1965) reported that one rat began feeding within minutes after the VMH had been destroyed during consciousness by thermocoagulation via implanted electrodes. Preliminary studies in this laboratory indicated that radio-frequency destruction of the VMH using various electrode configurations often produced various degrees of behavioral disruption that interfered with feeding behavior. Electrolytic lesions between monopolar electrodes positioned at homologous VMH coordinates also consistently produced tonic seizure activity. In the present study, the VMH of conscious rats was destroyed with minimal behavioral disruption when electrolytic current was passed between bipolar electrodes.

\section{METHOD}

\section{Subjects}

Eighteen Long-Evans female hooded rats were initially food deprived and trained to barpress for food reward (45-mg Noyes pellets) in Lehigh Valley operant conditioning chambers. After a minimum of 100 rewarded barpresses, each rat was anesthetized with sodium pentobarbital $(50 \mathrm{mg} / \mathrm{kg})$ and chronic indwelling bipolar electrodes were bilaterally implanted in the VMH and secured to the skull using standard stereotaxic surgery technique. The bipolar electrodes (MS-303-018-312-SS-008) were obtained from Plastic Products Company, Roanoke, Virginia. The coordinates for the implants were: $\mathrm{AP}=5.6, \mathrm{H}=-3.5, \mathrm{~L}=0.7$, according to de Groot (1959). Each twisted wire electrode was insulated except at its conical tip, and the poles were separated by the thickness of the insulation.

\section{Procedure}

Following a minimal recovery period of 3 days with free access to food (Wayne Lab Blox) and water, all rats were tested daily for 17 days in the operant chambers. The total number of barpresses during $1-\mathrm{h}$ test sessions was recorded. On the first day following $24 \mathrm{~h}$ of food deprivation, each barpress was rewarded with a pellet of food. Every fifth barpress (FR-5) was rewarded throughout the remaining 16 test sessions. The only food given to the rats during the first 5 days had to be earned in the operant chambers. This procedure was used to establish firmly barpress responding in hungry rats. Water was available at all times during the experiment, in both operant chambers and home cages.

For the remainder of the experiment, food was freely available in the home cages for the rats in Group $0(\mathrm{~N}=7)$. The rats in Group $2(\mathrm{~N}=8)$ and in Group $4(\mathrm{~N}=3)$ were treated similarly, except that food was removed 2 and $4 \mathrm{~h}$ prior to daily testing, respectively. Body weight and food intake were recorded daily. On Days 6-12, each rat was placed in a small Plexiglas enclosure for several minutes after the electrodes had been connected to the dc power supply. The rats in Group 0 were then immediately placed in the operant chambers, whereas the rats in Groups 2 and 4 were returned to their home cages, and were placed in the operant chambers 2 and $4 \mathrm{~h}$ later, respectively. This procedure was used both to habituate the rats to electrode attachment, and to establish a baseline of responding for food reward after 0,2 , and $4 \mathrm{~h}$ of food deprivation.

Immediately upon entering the Plexiglas enclosure on Day 13, the VMH was destroyed unilaterally via one of the chronically implanted electrodes. The contralateral lesion was produced immediately thereafter, using the same current parameters $(2.0 \mathrm{~mA}$ for $20 \mathrm{sec})$. The rats typically sat motionless as the lesions were produced, although occasionally some limb movement would occur. There was no vocalization, and none of the rats displayed behavior indicative of discomfort. Often the only indication that the lesions were being produced was the needle movement across the face of the milliammeter. The rats did not resist capture when the electrode connections were removed immediately after lesioning. The present procedure can thus be used to produce electrolytic destruction of the VMH in 
Table 1

Mean Number of Barpress Responses and Mean Daily Food Intake in Grams for Selected Test Days

\begin{tabular}{|c|c|c|c|c|c|c|c|c|}
\hline \multirow[b]{2}{*}{ Group } & \multirow[b]{2}{*}{$\mathrm{N}$} & \multirow{2}{*}{ 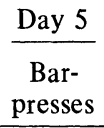 } & \multicolumn{2}{|c|}{ Days $10-12$} & \multicolumn{2}{|c|}{ Day 13} & \multicolumn{2}{|c|}{ Days 14-17 } \\
\hline & & & $\begin{array}{c}\text { Bar- } \\
\text { presses }\end{array}$ & $\begin{array}{c}\text { Food } \\
\text { Intake }(\mathrm{g})\end{array}$ & $\begin{array}{c}\text { Bar- } \\
\text { presses }\end{array}$ & $\begin{array}{c}\text { Food } \\
\text { Intake }(\mathrm{g})\end{array}$ & $\begin{array}{c}\text { Bar- } \\
\text { presses }\end{array}$ & $\begin{array}{c}\text { Food } \\
\text { Intake }(\mathrm{g})\end{array}$ \\
\hline 0 & 4 & 668 & 162 & 20 & 138 & $39 *$ & $424 *$ & $37 *$ \\
\hline 2 & 5 & 523 & 169 & 20 & $481 *$ & $36 *$ & $633 *$ & $35^{*}$ \\
\hline 4 & 3 & 584 & 190 & 21 & $817 *$ & $34 *$ & $785 *$ & $30 *$ \\
\hline $\mathrm{X}$ & 6 & 640 & 248 & 20 & 200 & 24 & 358 & 25 \\
\hline
\end{tabular}

Note-Lesions were made on Day 13.

*Within comparisons significantly different from baseline data on Days 10-12 at the .05 level.

conscious rats with minimal behavioral disruption.

All rats were tested in the operant chambers for 4 additional days following the day of lesioning. After 30 postlesion days of free access to food and water, body weights were obtained and the rats were perfused with saline and 10\% Formalin. Frozen sections of the brain were taken at 150 microns, and photographic enlargements of the unstained sections were used to assess the extent and location of tissue destruction.

\section{RESULTS AND DISCUSSION}

The data for six rats (three each from Groups 0 and 2) were not included in the analysis, since these rats did not overeat and become obese. The remaining rats displayed considerable hyperphagia with weight gains over 30 days ranging between 121 and $290 \mathrm{~g}$. Normal female rats of this age seldom gain more than $1 \mathrm{~g}$ per day. Although the VMH was partially destroyed in all hyperphagic rats, considerable portions often remained intact. The destruction typically occurred just medial to the plane of the fornix between the $\mathrm{VMH}$ and the lateral hypothalamic area. The lesions produced by this method were considerably smaller than when $2 \mathrm{~mA}$ is passed for $20 \mathrm{sec}$ between a monopolar anode and rectal cathode.

The results of the experiment are presented in Table 1. The data were collapsed across Days 10-12 and Days 14-17 for each rat, since the data were consistent across these days. The food-reinforced operant performance of rats maintained with free access to food in their home cages did not change appreciably during the hour immediately following the production of the lesions. A substantial increase in both barpressing and daily food intake, however, was maintained over the next 4 days of behavioral testing. In contrast to Group 0 rats tested either 2 or $4 \mathrm{~h}$ after lesion production significantly increased their rate of responding for food reward. These rats also maintained this higher level of performance during the next 4 days even though daily food intake had also increased.

Table 1 also presents the combined data for the six rats (Group X) that did not clearly overeat and become obese. These rats slightly increased $(4.5 \mathrm{~g})$ their daily food intake after lesioning, while operant responding for food reward remained essentially unchanged. The moderate increase in barpressing for Days 14-17 for this group was not significant $(\mathrm{t}=1.19$, $\mathrm{df}=10, \mathrm{p}>.20)$, and was produced primarily by one rat whose mean response rate was unusually high on Days 10-12 (408), and increased to 758 on Days 14-17.

In summary, rats that displayed obvious hyperphagia during the first $24 \mathrm{~h}$ after electrolytic destruction also increased their operant responding for food reward during the third hour after lesioning, whereas responding during the hour immediately following lesioning was not affected. Lesions that did not induce subsequent hyperphagia did not affect operant responding for food reward in sated rats.

These results are consistent with the recently reported data that indicate that rats with VMH lesions overeat and become obese because the lesion increases the rat's hunger motivation (Kent \& Peters, 1973; Peters, Sensenig, \& Reich, 1973; Peters \& Reich, 1973; Wampler, 1973). Although rats barpress at low levels when essentially sated (Days 10-12), 2 h after lesions have been made (Day 13), they respond at much higher levels, as they did under conditions of food deprivation (Day 5). Comparisons of overall levels of responding on Day 5 with postlesion performance are not meaningful, however, because of the extensive testing on the reinforcement schedule during the intervening days.

Rats begin feeding within several minutes after the intracranial administration of procaine to the medial hypothalamus via implanted cannula (Epstein, 1960). The procedure described here to produce lesions in conscious rats was first used to determine the latency of onset of feeding behavior following VMH destruction (Sensenig, 1972). Although some rats did begin feeding shortly after the lesions were made, this effect occurred both in rats that did and in those that did not subsequently become obese. There also was only a slight increase in the amount of food consumed during the hour immediately following the lesion. This result parallels the findings of the present study for the hour immediately following lesioning and contrasts with the effects induced by procaine administration. Reynolds and Simpson (1969), however, were also unable to obtain reliable increments in food intake during the hour following procaine anesthetization of the $\mathrm{VMH}$. In the present study, it is possible that the neural tissue continues to function for some period of time following the passage of current. It is also possible that the current disrupts normal brain functioning and therefore masks possible behavioral changes that would occur immediately following the passage of current. 


\section{REFERENCES}

Balagura, S., \& Devenport, L. D. Feeding patterns of normal and ventromedial hypothalamic lesioned male and female rats. Journal of Comparative \& Physiological Psy chology, 1970, 71, 357-364.

Brobeck, J. R., Tepperman, J., \& Long, C. N. H. Experimental hypothalam ic hyperphagia in the albino rat. Yale Journal of Biology \& Medicine, 1943, 15, 831-853.

de Groot, J. The rat forebrain in stereotaxic coordinates. Transactions of the Royal Netherland Academy of Science, $1959,52,1-40$.

Epstein, A. N. Reciprocal changes in feeding behavior produced by intrahypothalamic chemical injections. American Journal of Physiology, 1960, 199, 969-974.

Hetherington, A. W., \& Ranson, S. W. Hypothalamic lesions and adiposity in the rat. Anatomical Record, 1940, 78, 149-172.

Hoebel, B. G. Hypothalamic lesions by electrocauterization: Disinhibition of feeding and self-stimulation. Science, 1965 $149,452-453$

Kent, M. A., \& Peters, R. H. Effects of ventromedial hypothalamic lesions on hunger motivated behavior in rats. Journal of Comparative \& Physiological Psychology, 1973, 83. 92-97.
Peters, R. H., \& Reich, M. J. Effects of ventromedial hypothalamic lesions on conditioned sucrose aversions in rats. Journal of Comparative \& Physiological Psychology, 1973, 84 502-506.

Peters, R. H., Sensenig, L. D., \& Reich, M. J. Fixed-ratio performance following ventromedial hypothalamic lesions in rats. Physiological Psychology, 1973, 2, 136-138.

Reynolds, R. W., \& Simpson, C. W. Chronic infusion studies on the hypothalamic regulation of food intake. Annals of the New York Academy of Sciences, 1969, 157, 755-757.

Sensenig, L. D. Effects of electrolytic ventromedial hypothalamic lesions in conscious rats on hunger motivated behavior. Unpublished master's thesis, Iowa State University, November, 1972

Wampler, R. S. Increased motivation in rats with ventromedial hypothalamic lesions. Journal of Comparative \& Physiological Psychology, 1973, 84, 275-285.

(Received for publication October 18, 1973; revision received February 7,1974 .) 